\title{
Becoming a Teacher in the United States: Are Attitudes of Incoming Candidates Malleable?
}

\author{
By Sheryl O'Sullivan ${ }^{*}$
}

In the United States over the course of the last few decades, teacher education programs have been intentionally truncated. This often leaves teacher educators somewhat discouraged as to whether they are able to make any differences in teacher candidates during this relatively short period of time. Research seems to say that while we can teach prospective teachers specific knowledge and skills, we will find it much more difficult to change teacher attitudes or dispositions. The study reported in this article examines whether beliefs about teaching change during a two and one-half year undergraduate teacher education program. The study recorded the beliefs and attitudes of students as they entered a teacher education program and compared these with their attitudes upon graduation five semesters later, using a semantic differential instrument that demonstrates differences in perceptions of certain words. The results of this study are presented, and then this study is compared to a similar study undertaken with students in a one-year teacher education program. Finally, implications of the study for teacher education programs are discussed.

In the United States, the teaching profession and teacher preparation programs have been the perennial targets of wide-ranging but largely illinformed criticism. At least beginning with the 1983 publication of A Nation at Risk (National Commission on Excellence in Education), teachers have borne the brunt of all the evils of the United States from economic woes to global warming. Through it all, generation after generation of teachers have kept right on. We find them meeting their classes, honing their craft, and shielding their students to the best of their abilities against the worst excesses of United States educational policies.

Teacher preparation programs, especially those traditional programs housed in universities, have also been routinely criticized for failing to produce more able teachers. The same distrust and lack of respect that is unthinkingly heaped upon teachers themselves is also extended to the programs which educate these teachers. This has resulted in increasing governmental intervention and control in teacher education. The simplest area to target for this has turned out to be the curriculum of teacher education. Because the knowledge teachers possess is relatively easy to test, United States

${ }^{*}$ Professor of Education, Gordon State College, Georgia, USA.

https://doi.org/10.30958/aje.1-1-4

doi=10.30958/aje.1-1-4 
governmental policies have focused on what teachers should know and be able to do. These policies severely limit the time students may engage in teacher education while concurrently increasing the facts beginning teachers must possess. Yet, happily, teachers in the United States have continued to be overwhelmingly successful on state and national teaching examinations. Knowledge and skills, apparently, are not that difficult to impart, but wisdom is another matter.

We are reminded by Hansen (2001) that '...the most important factor in the practice of teaching is the person who occupies the role of teacher" (p. 20). While curriculum, pedagogy, management techniques, and the like, are all important features in classroom success, nothing is more important than the actual person of the teacher. To put this into the parlance of United States educational accreditation bodies, the knowledge and skills of teaching are important, but so too are teaching dispositions. As noted above, the knowledge and skills of teaching are relatively easy to identify, impart and test. Teaching dispositions, however, are turning out to be a much thornier problem. Not only are these dispositions harder to identify and test, but they seem to be extremely difficult to impact. Numerous studies (Wideen et al. 1998) have noted that the dispositions of incoming prospective teachers are resistant to change, and any change that does take place will take time. Yet, if the person of the teacher is the most important factor in good teaching, the dispositions, attitudes and beliefs of teachers are not inconsequential.

The study reported in this article deals with the above traits which more closely align with the wisdom of teaching rather than the knowledge and skills of the act. This article first considers the characteristics of incoming teachers in the United States, the difficulties of changing these incoming attitudes about teaching and the advisability of working to change these dispositions. Next it reports on a study of teaching dispositions that employed the research tool of the semantic differential to measure these attitudes. The results of this study are also briefly compared to a previous study using the same method with a different population. Finally, recommendations are made for using the findings of this study.

\section{Review of Literature}

Three areas are addressed in this review of research. These include the characteristics of teachers in the United States, the difficulties of effecting change in teacher attitudes, and the advisability or need for change in these beliefs. Throughout this article, the terms disposition, attitude and belief are considered to be roughly synonymous and refer to a conviction or habitual way of thinking about various aspects of teaching. 


\section{Characteristics of Teachers in the United States}

The teaching population in the United States tends to be a very stable demographic group over time (Feistritzer, 2011). According to the National Center for Educational Statistics (NCES, 2009), teachers in the United States continue to be overwhelmingly white and female. In 2007-08, the most recent year for which data are available, Caucasian teachers made up $83.5 \%$ of all teachers. In schools with high socio-economic status students, the percentage was an astounding 91.9\%. In all schools, African-American teachers made up only $6.7 \%$ of teachers and Hispanic teachers comprised only $6.9 \%$. Only $1.3 \%$ of all teachers in the United States in 2007-08 were Asian.

In addition to this lack of racial diversity among teachers, there is also a lack of gender equity. According to the same NCES statistics cited above, $74.6 \%$ of all teachers in the United States are female. And this percentage rises to almost $85 \%$ when only elementary teachers are considered.

This lack of ethnic and gender diversity might not matter that much if the students these teachers are teaching also lacked diversity. This is not the case, however. Roughly $42 \%$ of students in the United States are students of color (Zumwalt, 2008) with Hispanics representing the fastest growing minority group. This Hispanic population also is more likely to speak English as a second language which presents another challenge to the white, monolingual (English-speaking) population of teachers.

In addition to demographical stability of the teaching force, there is also evidence that this group enters teaching with firmly held beliefs and attitudes about teaching. In a meta-analysis of 93 studies on learning to teach, Wideen, Mayer-Smith and Moon (1998) noted that incoming teachers who were just beginning their journeys toward becoming teachers already considered themselves above average in almost all teaching skills. These beginners viewed teaching as a rather simple act of knowledge transfer and considered themselves already proficient at that task. And this strongly homogeneous group of teachers often unthinkingly expected their increasingly diverse students to be mirrors of themselves, learning basically as the teacher had learned in a teacher-directed, skills-based, transmissive classroom. As the discrepancy between the teaching population and student population becomes ever greater, it will be important to ask whether perpetuating current teacher beliefs is the correct path for United States schools.

\section{Difficulties of Changing Prior Beliefs}

Unfortunately, the dispositions or beliefs about teaching are amazingly resistant to change. Boger and Boger (2000) remarked on the enduring quality of these beliefs, and the Wideen et al. (1998) meta-analysis mentioned earlier concluded that teacher education programs had little effect on the firmly held beliefs of prospective teachers. Labarree (2008) summed up the problem nicely by saying, 'Teaching is an extraordinarily difficult job that looks easy' (p. 298). 
One reason for this relative over-confidence of incoming teachers can be explained through a classic sociological study by Lortie (1975) in which the phrase 'apprenticeship of observation' was coined. Prospective teachers have already been observing teaching as students for something like 15 years before they enter a teacher education program. This gives these students the mistaken impression that they already know everything they need in order to teach well. Coupling this with the many years of in-service education teachers receive through their jobs, it is easy to see why Richardson (1996) would label teacher education as a weak intervention sandwiched as it is between decades of observation and professional practice.

Another explanation for the resistance to change of these firmly held beliefs about teaching comes from the theories about the strength of paradigms in establishing what we are willing to see. According to paradigm theory, we all will see what we expect to see and be unable to see what does not fit our paradigm. Put in terms of classroom behavior, if a teacher expects effective teaching to involve transmissive, skills-based, textbook-oriented instruction, she will only recognize this behavior as successful. Students who learn in different ways will be considered deviant, and other types of instruction will be considered ineffective if they are acknowledged at all. Cochran-Smith and Zeichner (2005) summed this up well by saying, 'Teaching practices and beliefs are mediated by numerous factors, including their [teachers'] prior beliefs and experiences...' (p. 15).

\section{Impacting the Prior Beliefs of Prospective Teachers}

Since the incoming beliefs and attitudes of prospective teachers are so firmly entrenched, yet since these beliefs are also so important to determining future teaching behaviors, the question becomes one of some urgency. Can the very short intervention known as teacher education have any hope of modifying the incoming beliefs of these young teachers? While numerous studies (Wideen et al., 1998; Boger \&Boger, 2000; Richardson, 1996) have confirmed that these incoming beliefs will not be easily altered, there is a growing body of literature which point to practices that might be effective.

In general, this literature emphasized the development of a thinking teacher who does not leave her incoming beliefs unexamined. Numerous authors (Gould, 2000; Howard \& Aleman, 2003; Darling-Hammond \& Bransford, 2005) call for the need for students to systematically examine their incoming attitudes during teacher education programs. The benefit of reflection and a reflective attitude about prior beliefs was noted as paramount in a Darling-Hammond (2006) study of effect teacher education programs. The exemplary programs highlighted in this study do many things right, but one clear strength of these programs is the requirement for students to evaluate their teaching beliefs and modify these if necessary.

Beyond the need for prospective teachers to systematically examine their prior beliefs about teaching, one body of literature is advocating an even more radical stance. Sockett (2008) used the term moral agent and Hansen (2001) called for the development of moral sensibilities. Noddings (2006) argued for 
critical thinking and terms self-understanding as the most important goal of teacher education. Clearly these authors feel that the mere examination of teaching beliefs is only a first step to the development of the person who is the teacher.

In the United States, these voices are still relatively muted, and it is clear from this review of research that deeply entrenched prior beliefs and attitudes about teaching will not be easily altered. The study now presented in this article considers two questions relating to teaching beliefs. First, what are the incoming beliefs of prospective teachers, and can or should these beliefs be altered? And second, will the length of the teacher education program have any effect on whether the incoming attitudes of prospective teachers change? The current study, completed in 2012, will be presented first, and then this will be briefly compared to a similar study completed in 2002 .

\section{Method}

In the current study, the investigator sought to determine the prior beliefs of upper division undergraduate students as they began a 2.5 year teacher education program leading to a baccalaureate degree. These incoming beliefs were then compared to the attitudes of the same students as they exited the program. Specifically, this study focused on the beliefs these students held about six basic concepts pertaining to teaching: teacher, student, classroom management, lesson plans, teaching of reading and student assessment.

Subjects: The investigator conducted this study at a mid-sized public college in the southeastern United States. The teacher education program was designed to take five semesters to complete, and students undertook the entire program as a cohort group, taking all courses together in the same order. While cohort models such as this are common at the graduate level of education in the United States, they are relatively uncommon as a way of delivering undergraduate education, making the cohesion of this program somewhat unusual.

An assessment instrument dealing with beliefs about teaching was administered to these students as they entered the teacher education program in the fall of 2010, and then re-administered as they exited the program five semesters later in the spring of 2012. Thirty-nine matched pairs of students completed the two assessments. This population closely mirrored the general teaching population in the United States as being largely Caucasian, female and monolingual. In this study, 34 of the students were Caucasian and five of the students were of African-American descent. None of the subjects were Hispanic or Asian. Only five of the 39 subjects were male. The students ranged in age from 18 to 39 years, but were mostly traditional-aged students with 29 of the subjects being between the ages of 18 and 23 .

Instrument: The instrument used in this study was called the semantic differential. This relatively little-known instrument was originated in 1957 by 
Osgood, Suci and Tannenbaum and later shown to be valid for measuring attitudes by numerous studies reviewed in Kerlinger (1973). The semantic differential instrument measures the meaning of any concept along three dimensions. These dimensions are: evaluation, potency and activity. To measure beliefs held about various concepts the technique makes use of bipolar adjectives. While any concept can be chosen to be measured, the bi-polar adjectives must be chosen from a thesaurus of validated adjectives (Osgood, et al, 1957).

The current study chose to measure the attitudes subjects held about the concepts of teacher, student, classroom management, lesson plans, teaching of reading and student assessment. For each concept, three bi-polar adjectives were chosen in each of the three dimensions. In each scale, the first three bipolar adjectives referred to evaluation, the second three to potency, and the last three to activity. This meant that each concept contained a total of nine items. Since six concepts were assessed, a total of 54 items were measured. Figure 1 shows an example of one of the concept measurements, the concept of teacher.

Figure 1. Semantic Differential Instrument for the Concept of "Teacher"

\section{TEACHER}

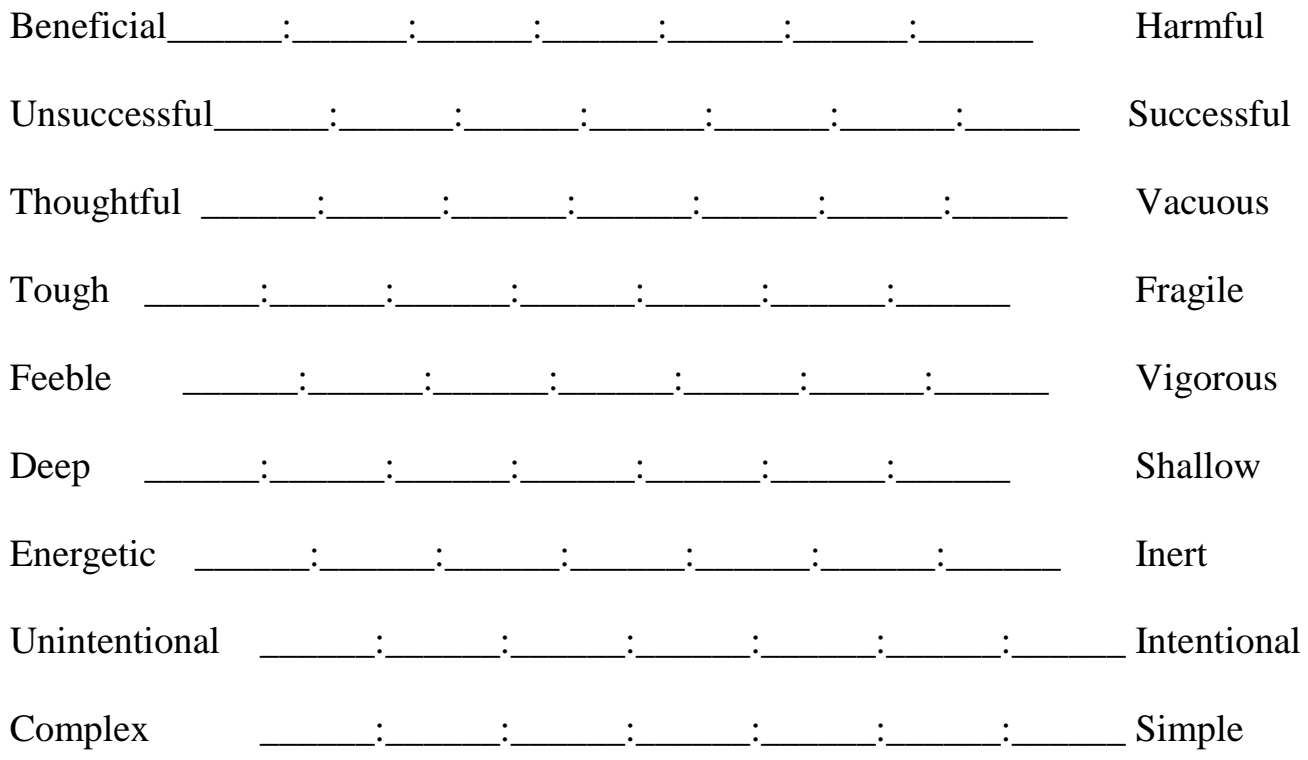

Similar pages were developed for the other concepts. The bi-polar adjectives for each concept were specially chosen for that concept. They were arranged so that positive and negative semantic meanings were not always on one side. In Figure 1, for example, the terms beneficial, successful, thoughtful, tough, vigorous, deep, energetic, intentional and complex all carried the highest positive value of 7 regardless of their placement on the assessment form. This was done to deter subjects from simply marking straight down in any one column. Figure 2 displays the complete list of the concepts and bi-polar adjectives used in this study. 
Figure 2. Bi-polar Adjectives by Concept

\begin{tabular}{|c|c|c|}
\hline TEACHER & STUDENT & CLASSROOM MGMT \\
Beneficial/harmful & Intelligent/unintelligent & Merciful/merciless \\
Successful/unsuccessful & Good/bad & Approving/disapproving \\
Thoughtful/vacuous & Successful/unsuccessful & Useful/useless \\
Tough/fragile & Strong/weak & Tough/fragile \\
Vigorous/feeble & Brave/cowardly & Strong/weak \\
Deep/shallow & Wide/narrow & Vigorous/feeble \\
Energetic/inert & Moving/still & Active/passive \\
Intentional/unintentional & Complex/simple & Intentional/unintentional \\
Complex/simple & Motivated/aimless & Complex/simple \\
\hline LESSON PLANS & TEACHING OF & STUDENT \\
Beneficial/harmful & READING & ASSESSMENT \\
Important/unimportant & Important/unimportant & Voluntary/compulsory \\
Thoughtful/vacuous & Thoughtful/vacuous & Beneficial/harmful \\
Vigorous/feeble & Successful/unsuccessful & Wise/foolish \\
Thick/thin & Hard/soft & Hard/soft \\
Deep/shallow & Vigorous/feeble & Strong/weak \\
Energetic/inert & Deep/shallow & Deep/shallow \\
Laborious/effortless & Active/passive & Active/passive \\
Motivated/aimless & Intentional/unintentional & Motivated/aimless \\
& Multiple/single & Multiple/single \\
\hline
\end{tabular}

Procedure: This longitudinal study was conducted in two phases. During the orientation session students attended at the beginning of their cohort teacher education program in the fall of 2010, students completed the pre-test form of the semantic differential. These same students then completed the posttest form of the instrument five semesters later as they exited the teacher education program. The two administrations were combined resulting in 39 matched pairs in which incoming and exiting attitudes could be compared. The administration of the pre-test also allowed the incoming attitudes of these students to be examined.

T-tests (two-tailed) were performed on the mean values of each of the 54 items on the semantic differential. A rigorous level of statistical significance $(\mathrm{p}<.03)$ was used in order to offset the chance of a Type 1 error which is more likely when so many t-tests are performed. Of the 54 items, eight yielded statistically significant changes at this level of rigor. Six of these represented statistically significant changes in a positive direction.

In examining the incoming attitudes of teacher candidates, the most obvious information is the extremely positive way in which these beginners viewed teaching. Table 1 shows the beginning mean values of this group for every concept under the three dimensions of evaluation, potency and activity. Since the highest score possible in each area was 7 , it is obvious that this group of prospective teachers viewed all of these concepts as good, strong and active. Three of the highest incoming values were in the area of evaluation, with the concepts of teacher, lesson plans and teaching of reading all achieving mean scores higher than 6.0. No incoming mean scores for this group of students fell 
below 5.0. These results confirm the results of other studies that have found prospective teachers to be exceedingly positive but idealistic.

Table 1. Mean Values of Incoming Teacher Education Students by Concept

\begin{tabular}{|l|l|l|l|l|l|l|}
\hline & Teacher & Student & Management & Planning & Reading & Assessment \\
\hline Evaluation & 6.35 & 5.60 & 5.75 & 6.72 & 6.73 & 5.86 \\
\hline Potency & 5.08 & 5.03 & 5.62 & 5.46 & 5.45 & 5.09 \\
\hline Activity & 5.36 & 5.38 & 5.99 & 6.16 & 5.97 & 5.61 \\
\hline Total & 5.56 & 5.33 & 5.78 & 6.11 & 6.04 & 5.52 \\
\hline
\end{tabular}

In comparing pre- and post-assessment results, only eight of the group means changed in statistically significant ways. Six of these were in a positive direction with the concept of teacher being seen as more potent and vigorous, the concept of student becoming more active, the concept of teaching of reading becoming more potent and more active, and finally, the concept of student assessment being seen as more active. Two items demonstrated statistically significant negative changes with the concept of student moving from complex to more simple and the concept of classroom management becoming more unintentional. While any negative movement must be seen as disappointing, considering the extremely high incoming values, these two changes may represent a predictable reversion to the mean.

\section{Comparison to Earlier Study}

The investigator was involved in a similar study in 2002 (O'Sullivan \& Jiang, 2004). In this previous study, the pre-/post-assessment method using an identical semantic differential instrument was used. Several differences in population and program should be noted. In the prior study, the teacher education program in which students were engaged was a two-semester, graduate program in a university in the southwestern United States. Students in this program had only one semester of coursework before beginning a full-time fieldwork component. While the students in the previous study were slightly older and ever-so-slightly more diverse, the two populations were generally comparable, with the main difference between the two studies being the duration of the teacher education programs.

There were several areas of agreement in the results of the two studies. Both groups displayed extremely high incoming values for every concept. Table 2 displays the mean values of both groups, and it is clear that nearly all incoming means for both groups fall between 5.0 and 6.5 on a 7.0 scale. The two groups also agreed in giving their highest scores to the value of the teaching of reading $(6.66 / 6 / 73)$ and to the value of lesson plans $(6.48 / 6.72)$. 
Table 2. Mean Values of Incoming Teacher Education Students in Comparison Studies

\begin{tabular}{|c|c|c|c|c|c|c|c|c|c|c|c|c|}
\hline & \multicolumn{2}{|c|}{ Teacher } & \multicolumn{2}{|c|}{ Student } & \multicolumn{2}{|c|}{ Management } & \multicolumn{2}{|c|}{ Planning } & \multicolumn{2}{|c|}{ Reading } & \multicolumn{2}{|c|}{ Assessment } \\
\hline & '02 & '12 & '02 & '12 & '02 & ' 12 & ‘02 & '12 & '02 & '12 & '02 & ' 12 \\
\hline Evaluation & 6.18 & 6.35 & 6.23 & 5.60 & 5.54 & 5.75 & 6.48 & 6.72 & 6.66 & 6.73 & 4.97 & 5.86 \\
\hline Potency & 5.32 & 5.08 & 5.73 & 5.03 & 5.83 & 5.62 & 5.57 & 5.46 & 5.77 & 5.45 & 5.05 & 5.09 \\
\hline Activity & 5.82 & 5.36 & 5.87 & 5.38 & 5.67 & 5.99 & 5.88 & 6.16 & 6.42 & 5.97 & 6.08 & 5.61 \\
\hline Total & 5.77 & 5.56 & 5.94 & 5.33 & 5.78 & 5.78 & 5.97 & 6.11 & 6.28 & 6.04 & 5.36 & 5.52 \\
\hline
\end{tabular}

The main difference between the two studies came in the changes observed from the pre- and post-assessment values. The 2012 group displayed eight statistically significant changes of which six (slightly more than 10\%) were positive. The 2002 group saw only two statistically significant changes and both of these were negative. For these two studies, while the number of positive attitudinal changes (6) was not great for the teacher candidates engaged in the five semester program, it far outdistanced the positive attitudinal changes $(0)$ in the abbreviated program. Just as has been found in other studies, incoming beliefs about teaching were resistant to change in these two studies. And any positive changes that did occur took place in the program of greater duration.

\section{Discussion}

The results of the current study (2012) were paradoxically both predictable and surprising. Predictably, the students in this study entered with extremely positive and idealistic views of teaching. They believed from the very first day that teaching was a powerful and important act, that students were active and good, and that lesson planning, the teaching of reading and student assessment were all extremely valuable. Many other studies as noted in the review of research have also found incoming teacher candidates to be a homogeneous group with firmly held positive beliefs about teaching.

Another area of the current study should also be seen as predictable and that is the relative lack of change in these incoming values during the course of a teacher education program. Again, as seen in the review of research, numerous studies have demonstrated that attitudes about teaching are resistant to change, perhaps because of the long "apprenticeship of observation" students have before beginning a teacher education program. Regardless of the reason, many other studies have shown that attitudes and beliefs about teaching do not change quickly or easily. It should be considered predictable, then, that the attitudes of the students in this study did not change dramatically.

However, even with all of the predictability of the results of this study, there is the surprising fact that six of the 54 variables did exhibit statistically significant positive changes. This is all the more surprising because the extremely high incoming values made statistically significant positive change difficult to achieve. These students began to see teaching as even more powerful than they had previously expected. They came to see the teaching of 
reading and student assessment as even more complex than they had thought. And they began to see their students as even more active participants in learning than they had come to believe during their own long years as students. While it would have been wonderful to see many more positive changes in attitudes in this group, the fact that numerous studies, including the 2002 companion study to this one, have noted no changes in attitudes, makes the results of this current study surprising and cause for some hope.

\section{Conclusion}

The first conclusion of this study and others referenced in this article must be positive. If we in the United States are indeed producing a homogeneous, self-propagating group of teachers for our classrooms, then we must rejoice and be glad they are such a positive, beneficent crowd. If their values are resistant to change, then we must surely take heart that these values are already ones conducive to respect for and nurturing of young people. It would be difficult to argue that a group of people who hold themselves, their students and their work in such high esteem are completely wrong-headed.

On the other hand, the beginning of this article made the case that there is a widening disconnection between the homogeneous, Caucasian, female, monolingual population of teachers in United States classrooms and their increasingly diverse students. Prospective teachers who begin teacher education with the idea that they have very little to learn about teaching because their students will learn in much the same way as they themselves learned are in for a rude awakening when their idealized views of teaching meet the realities of United States classrooms. Teacher education programs, while rejoicing in the positive beliefs prospective teachers hold, must also commit to helping these beginning teachers examine, challenge and deepen these views. Study after study, and this one besides, has found that these beliefs will not change quickly or without intentional effort. To continue to truncate and fragment teacher education will almost certainly lead to teachers in tomorrow's classrooms much like the teachers in today's.

\section{Recommendations}

The results of the two companion studies reported here and others lead to the following recommendations:

1. Teacher education programs must be exceedingly careful in the admissions process. If it is true, as appears to be the case, that incoming beliefs will change very little during a teacher education program, then it is imperative that we admit only those candidates who already hold the beliefs, attitudes and dispositions we consider positive for teaching. To admit candidates with 
questionable beliefs in the hope that these can be altered during the teacher education program flies in the face of considerable evidence and should be considered irresponsible.

2. If dispositions are considered of any importance in the formation of a teacher, then teacher education programs must be allowed, indeed encouraged, to change. De-emphasizing discreet skills and bit of knowledge and bringing intentional emphasis to the person who is the teacher is recommended. Programs which compel prospective teachers to confront unexamined beliefs and intentionally reflect upon these show the most promise for changing the attitudes of prospective teachers. This type of activity is not quick, and teacher education programs must be given sufficient time to engage in this type of teacher formation.

3. Additional research in two areas is recommended. First, investigations into exemplary programs show great promise and should be increased. If changing dispositions is our goal, which teacher education programs do this well, and how do they do it? Second, in both companion studies presented in this article, the group means for the six concepts did not change a great deal. However, the mean changes for some individual students were startling. Research into why some students changed so much while most did not would be fruitful.

In Exploring the Moral Heart of Teaching, David Hansen (2001) makes a case that teaching is much more than the sum parts of a teacher's knowledge and pedagogical skills. He argues that the moral sensibilities of the teacher are more important and that these traits can only be developed 'slowly, steadily, patiently' (p. 187). Perhaps these three adverbs should become our watchwords in teacher education. Prospective teachers come into our programs as strong, positive people, but turning these positive individuals into fine teachers will be slow, steady work requiring patience. All of those involved in teacher education in the United States, including teacher educators, state legislatures and teacher accreditation bodies, would do well to acknowledge that fact and begin this important work.

\section{References}

Boger, C.C. \& D. Boger (2000). 'Preservice teachers' explanation of their teaching behavior.' Journal of Instructional Psychology, 27(4): 217-223.

Cochran-Smith, M. \& K. Zeichner (2005). Studying teacher education: The report of the AERA panel on research and teacher education. Mahwah, NJ: Lawrence Erlbaum Associates.

Darling-Hammond, L. \& J. Bransford (eds.) (2005). Preparing teachers for a changing world. San Francisco, CA: Jossey-Bass. 
Darling-Hammond, L. (2006). Powerful teacher education: Lessons from exemplary programs. San Francisco, CA: Jossey-Bass.

Feistritzer, C.E. (2011). Profile of teachers in the U.S. 2011. Washington, D.C.: National Center for Education Information.

Gould, L. (2000). 'Changes in pre-service teachers' schema for understanding teaching.' Action in Teacher Education, 21(4): 90-100.

Hansen, D. T. (2001). Exploring the moral heart of teaching. Columbia, NY: Teachers College Press.

Howard, T. C. \& G. R. Aleman (2008). 'Teacher capacity for diverse learners: What do teachers need to know?' In: M. Cochran-Smith, S. Feiman-Nemser, \& D.J. McIntyre (eds.), Handbook of research on teacher education, $3^{\text {rd }}$ Ed., 157-174. New York: Routledge.

Kerlinger, F.M. (1973). Foundations of behavioral research $\left(2^{\text {nd }}\right.$ ed.). New York: Holt.

Labarree, D.F. (2008). 'An uneasy relationship: The history of teacher education in the university.' In: M. Cochran-Smith, S. Feiman-Nemser, \& D.J. McIntyre (eds.), Handbook of research on teacher education, $3^{\text {rd }}$ Ed., 290-306. New York: Routledge.

Lortie, D.C. (1975). Schoolteacher. Chicago: University of Chicago Press.

National Center for Educational Statistics (2009). Characteristics of public, private, and Bureau of Indian education elementary and secondary school teachers in the United States: Results from the 2007-08 schools and staffing. Available at: http://nces.ed.gov/pubs2009/2009324/tables/sass0708_2009324_t12n_03.asp. [8 January 2013].

National Commission on Excellence in Education. A nation at risk (1983). Washington, D.C.: U.S. Government Printing Office.

Noddings, N. (2006). Critical lessons: What our schools should teach. New York: Cambridge University Press.

Osgood, C.E., G.J. Suci \& P.H. Tannenbaum (1957). The measurement of meaning. Urbana, IL: University of Illinois Press.

O'Sullivan, S.L. \& Y.H. Jiang (2004). 'Becoming a teacher: Can fifth year programs influence the attitudes of teacher candidates?' Issues in Teacher Education, 13 (2): 57-69.

Richardson, V. (1996). 'The role of attitudes and beliefs in learning to teach.' In: J. Sikula, T. Buttery, \& E. Guyton (eds.). Handbook of research on teacher education, $2^{\text {nd }} E d$., 102-119. New York: Macmillan.

Sockett, H. (2008). 'The moral and epistemic purposes of teacher education.' In: M. Cochran-Smith, S. Feiman-Nemser, \& D.J. McIntyre (eds.), Handbook of research on teacher education, $3^{\text {rd }}$ Ed., 45-65. New York: Routledge.

Wideen, M., J. Mayer-Smith \& B. Moon (1998). 'A critical analysis of the research on learning to teach: Making the case for an ecological perspective on inquiry.' Review of Educational Research, 68(2), 130-178.

Zumwalt, K. \& E.Craig (2008). 'Who is teaching? Does it matter?' In: M. CochranSmith, S. Feiman-Nemser, \& D.J. McIntyre (eds.), Handbook of research on teacher education, $3^{\text {rd }}$ Ed., 404-423. New York: Routledge. 